Research Article

\title{
The Dark Side of Ridesharing in China: A Case Study of Qiangsheng Taxi
}

Tian Meng, Songyi Cai, You Qu, Evelyn Ng, Barney Tan, and Bo Zhu $\mathbb{D}$

Shanghai Sci-Tech Finance Institute, Shanghai University, Shanghai 200072, China

Correspondence should be addressed to Bo Zhu; zhubo@staff.shu.edu.cn

Received 9 September 2020; Revised 9 October 2020; Accepted 2 December 2020; Published 16 December 2020

Academic Editor: Tingsong Wang

Copyright (c) 2020 Tian Meng et al. This is an open access article distributed under the Creative Commons Attribution License, which permits unrestricted use, distribution, and reproduction in any medium, provided the original work is properly cited.

Our understanding of the negative implications of the sharing economy is limited, particularly from the perspective of the traditional businesses that are being displaced. To address this knowledge gap, this paper documents our ongoing study of Qiangsheng Taxi, the oldest and largest taxi company based in Shanghai, China. Our aim is to develop a preliminary process model based on the data collected to date that sheds light on the negative implications of ridesharing, one of the most recognized forms of the sharing economy. More specifically, our process model suggests that there are contextual conditions that are particularly conducive to the growth of ridesharing platforms in China and how they accumulate resources, which give rise to four negative outcomes for the traditional taxi business. These negative outcomes, in turn, reinforce the prevailing contextual conditions to form a vicious cycle that exacerbates the negative influence of the ridesharing platforms even further.

\section{Introduction}

In recent years, a new consumption paradigm known as the sharing economy has been on rapid rise all over the world as it generates many benefits and allows people to access idle goods and resources without having to own them [1]. The sharing economy is defined as the "peer-to-peer-based activity of obtaining, giving, or sharing the access to goods and services, coordinated through community-based online services" ([2], p. 2047). It is predicated that the global sharing economy will reach $\$ 335$ billion by 2025 [3]. In the transportation sector, for example, ridesharing has become a very popular form of the sharing economy, with large number of ridesharing platforms, such as Uber, Lyft, and $\mathrm{DiDi}$, operating all over the world [4]. With ridesharing, people can use their smartphones to access the ridesharing platform to request transportation service and the platforms match the requests with available private cars in real time. As it is more convenient than street-hailing and their prices tend to be lower, the ridesharing platforms have grown rapidly to become a popular mode of travel. This has caused disruption to the existing taxi industry and resulted in competition and regulatory concerns [5]. In particular, there is a growing realization that ridesharing may lead to the exploitation of labor (e.g., unsafe working conditions and lower than minimum wages) and fares poorly in checking undesirable provider behaviors (e.g., sexual harassment by Uber drivers), and its ecological impact may be overstated [6].

Reflecting the growing awareness of these issues, a number of researchers within academia have now turned their attention to examining the impact of the sharing economy and offering prescriptions on mitigating its potential negative implications (e.g., [7]). And yet, these emerging works tend to be conceptual in nature and not corroborated by empirical evidence. In addition, the sharing economy may have a negative impact on the incumbent industries that it is attempting to displace as well, precipitating the loss of revenue and jobs or even the exit of traditional businesses [8]. However, there have been only a handful of studies undertaken from the perspective of these traditional businesses, and the mechanisms that underlie the negative influence of the sharing economy on these businesses have not been adequately studied. Addressing these knowledge gaps is important if we are to understand the real impact of the sharing economy more fully, which may be 
important for policy makers to formulate effective legislation to regulate the sector, and for traditional businesses to develop countermeasures to the challenges and threats that they are facing.

This paper documents an ongoing study aimed at addressing these knowledge gaps. More specifically, based on a case study of Qiangsheng Taxi, the oldest and largest taxi company based in Shanghai, China, our aim is to develop a preliminary process model that sheds light on the negative implications of ridesharing (i.e., one of the most widely recognized forms of the sharing economy represented by platforms such as Uber and Didi-see [9]) from the perspective of a traditional taxi business. Accordingly, our research question is as follows: How does the sharing economy influence the business of a traditional company?

\section{Literature Review}

2.1. Existing Research on the Sharing Economy. The sharing economy is based on the principle of sharing access to products and services in peer-to-peer (P2P) markets [10]. This principle of sharing in itself is not new [11]: the sharing of forestry machinery and the services of public libraries, for example, are manifestations of the principle in the businessto-business (B2B) and business-to-consumer (B2C) domains, respectively [12]. The extension of the principle of sharing into the $\mathrm{P} 2 \mathrm{P}$ domain, however, is a relatively recent development that is driven by economic crises and an increasing awareness of the importance of protecting the environment [10]. This development is made possible by advances in information and communications technology (ICT), changing consumer preferences, the proliferation of collaborative web communities, and the emergence of social commerce [2].

Sharing economy businesses tend to be digital platforms that are based on an online website and/or a mobile app [13]. These platforms can be classified into four categories arranged in a $2 \times 2$ matrix depending on whether they are for-profit or not-for profit, and whether they have a P2P or $\mathrm{B} 2 \mathrm{C}$ business model [1]. Of the four categories, the forprofit/P2P platforms have arguably been the most visible with the greatest economic impact: platforms such as Uber and Airbnb that fall under this category have become multibillion-dollar businesses that are operating in numerous countries across the globe (i.e., 60 and 191 countries, respectively). As a result, this category of platforms has been the most extensively studied to date (e.g., [8, 14]). The majority of the existing research on the sharing economy, in particular, can be classified into three main streams.

The first is centered on the adoption of collaborative consumption. Studies aligned with this stream are typically seeking to identify the antecedent factors that promote participation on a sharing economy platform, as either a supplier or a consumer of a product/service. For instance, Hamari et al. [2] found that sustainability (i.e., a preference for greener consumption), enjoyment of the activity, and economic gains were the primary participation drivers for the sharing economy. However, the influence of sustainability is only significant if it is also associated with a positive disposition toward this new mode of consumption, which suggests that the factor may only be important for those who are environmentally conscious. In a similar vein, Zhu et al. [15] found that the functional, emotional, and social value of a sharing economy platform will have a positive influence on the attitude of its users, which will translate to the intention to adopt.

The second research stream focuses on the nature and development of sharing economy platforms. Studies belonging to this research stream are generally attempting to explain the components and functions of these platforms, as well as the strategies and activities that facilitate their development. Puschmann and Alt [12], for example, described the components of the strategies, processes, and systems that constitute a sharing economy platform, and suggested that the platform as an intermediary has to perform the roles of listing, contracting, billing, fulfillment, and rating. On the other hand, Tan et al. [16] described the developmental trajectory of a sharing economy platform and argued that a platform should first emphasize its pro-social objectives before ensuring business viability and, finally, striking a balance between the market and social logics.

The third research stream is centered on the implications of sharing economy platforms. Studies of this stream are mainly aimed at investigating the economic, environmental, and social impact of these platforms. For instance, Martin [17] examined the existing discourse surrounding the sharing economy and found that the phenomenon is typically framed as a combination of (1) an economic opportunity, (2) a more sustainable form of consumption, and (3) a pathway to a decentralized, equitable, and sustainable economy. But at the same time, the sharing economy may also be criticized for (4) creating unregulated marketplaces, (5) reinforcing the neoliberal paradigm, and (6) being an incoherent field of innovation. Adopting a more specific focus, Zervas et al. [8] investigated the impact of Airbnb on the incumbent hotel industry and found that the sharing economy platform reduced the revenue of traditional hotels by $8-10 \%$, with lower-priced hotels and hotels that do not cater to business travelers the most affected. This impact is mostly due to lower prices on Airbnb and is most pronounced when there is a spike in demand, suggesting that sharing economy platforms have an advantage in terms of its ability to flexibly scale its supply to meet demand.

\subsection{The Potential Negative Implications of the Sharing} Economy. Within the third research stream (refer to Table 1), our review of the literature reveals at least two research gaps in relation to our research question. First, although the emerging works in this area are demonstrating an awareness of the potential negative implications of the sharing economy, much of the present discourse is anecdotal in nature (e.g., $[1,18])$. The potential negative implications that have been raised in the existing literature include a lack of concern for the interests of related stakeholders, the creation of shortages for long-term asset owners, the amplification of social biases, the perpetuation of unfair regulatory regimes, the exploitation of labor, and a 
TABLE 1: Literature review.

\begin{tabular}{lcc}
\hline Author/year & Article/title & Source \\
\hline & & \\
$\begin{array}{l}\text { Hart et al. } \\
(2016)\end{array}$ & Do We Need Rules for "What's Mine Is Journal of Business Research \\
& Yours"?
\end{tabular}

The sharing economy is based on the principle of sharing access to products and services in peer-to-peer (P2P) markets.

Hart et al. Do We Need Rules for "What's Mine Is Journal of Business Research
(2016)
Yours"? The extension of the principle of sharing into the $\mathrm{P} 2 \mathrm{P}$ domain, however, is a relatively recent development that is driven by economic crises and an increasing awareness of the importance of protecting the environment.

\begin{tabular}{|c|c|}
\hline Belk (2014) & $\begin{array}{l}\text { You Are What You Can Access: Sharing } \\
\text { and Collaborative Consumption Online }\end{array}$ \\
\hline
\end{tabular}

The principle of sharing is not new.

The development is made possible by advances in information and communications technology (ICT), changing consumer preferences, the proliferation of collaborative web communities, and the emergence of social commerce.

Hamari et al. (2016)

The Sharing Economy: Why People Participate in Collaborative Consumption
Journal of the Association for Information Science and Technology

Sustainability (i.e., a preference for greener consumption), enjoyment of the activity, and economic gains were the primary participation drivers for the sharing economy. However, the influence of sustainability is only significant if it is also associated with a positive disposition toward this new mode of consumption, which suggests that the factor may only be important for those who are environmentally conscious. Sharing economy businesses tend to be digital platforms that are based on an online website and/or a mobile app.

The platforms can be classified into four categories arranged in a $2 \times 2$ matrix depending on whether they are for-profit or not-for profit, and whether they have a P2P or B2C business model.

\begin{tabular}{lcc}
\hline Cramer and & Disruptive Change in the Taxi Business: \\
Krueger (2016) & The Case of Uber & \\
& American Economic Review
\end{tabular}

The category of platforms has been the most extensively studied to date.

The functional, emotional, and social value of a sharing economy platform will have a positive influence on the attitude of its users, which will translate to the intention to adopt.

Inside the Sharing Economy:

Zhu et al. (2017) Understanding Consumer Motivations behind the Adoption of Mobile Applications
International Journal of Contemporary Hospitality Management
The developmental trajectory of a sharing

economy platform, and it argues that a

platform should first emphasize its pro-social objectives before ensuring business viability and, finally, striking a balance between the market and social logics.

The sharing of forestry machinery and the services of public libraries, for example, are manifestations of the principle in the businessto-business (B2B) and business-to-consumer (B2C) domains, respectively.

The developmental trajectory of a sharing economy platform and it argues that a platform should first emphasize its pro-social objectives before ensuring business viability and, finally, striking a balance between the market and social logics. 
lack of control over undesirable provider and consumer behaviors, among others (see [7]). However, few of them have been corroborated or verified by empirical investigation. Without empirical support, the arguments presented in these works can only remain in the realm of guesswork and assumptions, from which it is difficult to derive theories and insights for the advancement of knowledge in this area.

Second, of the existing works on the negative implications of the sharing economy, there are only a handful that have been conducted from the perspective of the traditional firms that the sharing economy platforms are displacing. One exception is the aforementioned study by Zervas et al. [8]; but even though the impact of Airbnb on traditional hotels has been ascertained, the relationship uncovered remains a "black box" because the precise mechanisms through which the platform affects the hotels fall beyond the scope of the paper. Similarly, Chang [19] discovered that the entry of Uber in Taiwan reduced taxi revenues by approximately $12 \%$ in its initial year and $18 \%$ by the third year of its entry, but once again the underlying reason proffered for this effect is merely speculative in nature (i.e., a substitution effect) and has been contradicted in other studies (see [20]). To address these research gaps, our aim is to conduct an in-depth investigation into the underlying mechanisms through which the negative implications of the sharing economy manifest from the perspective of a traditional business. In the following sections, we will describe our research approach and the preliminary findings from our ongoing study.

\section{Research Method}

The case research method is especially appropriate for our study because its strengths lie in exploring 'how' research questions [21], understudied and multi-faceted phenomena, and processes that cannot be separated from their contexts [22] - all conditions that are relevant to our study. To address our research question, we identified two criteria for case selection. First, the selected organization should be a traditional firm whose business has been severely affected by a sharing economy platform. The extent of severity is important because our study is aiming to capture the potential magnitude of the negative implications of the sharing economy. Second, the selected organization should be a commercially successful business and a market leader within the industry prior to the inception of the sharing economy. This is to rule out possible alternative explanations for the negative effects that we may uncover (e.g., sub-par organizational performance may be attributed to a general lack of competitiveness instead). The case of Qiangsheng Taxi is particularly appropriate for our study because not only is the firm the oldest and largest taxi company in Shanghai, China, but its historically viable taxi business has seen its revenue drastically diminished since the inception of ridesharing in 2012. This makes Qiangsheng a revelatory or extreme case [23] for the purpose of our study.

Qiangsheng Taxi was founded in Shanghai as Xiangsheng Automobile in 1919. In 1954, Xiangsheng was renamed the Shanghai Taxi Company, and within a short span of 2 years, it acquired and merged with 16 other car dealers in the city to become the market leader within the local taxi industry, a position that it has held for over 60 years. The firm became publicly listed on the Shanghai Stock Exchange in 1992 and acquired its present name in 2001. Qiangsheng Taxi is currently a state-owned holding company under the corporate umbrella of the Shanghai Jiushi Group. It currently has an asset base valued at approximately US $\$ 868$ million, 35,000 employees, and a fleet of over 13,000 vehicles (including taxis and rental cars). Qiangsheng is known as a technology leader within the industry as well, pursuing an array of cutting-edge technological innovations such as establishing an intelligent dispatching center, installing location tracking and speed monitoring devices in all of its vehicles, and developing a traffic management system that intelligently routes its vehicles based on traffic and road conditions. Qiangsheng currently has five main lines of business, including its taxi, car rental, automobile servicing, travel, and property investment divisions. The first two, in particular, have felt the brunt of the market revolution brought about by the sharing economy.

3.1. Data Collection and Analysis. Case access was granted in May 2018 and the study has been ongoing for the past 12 months. The study was designed with two main phases: a preparatory phase and a fieldwork phase. The focus of the preparatory phase was to collect and analyze data from a variety of secondary sources so as to gain an overview of the case organization as well as the industry in which it operates. The emphasis of the ongoing fieldwork phase, on the other hand, is to collect primary data that are specific to our research question and explore the implications of ridesharing on Qiangsheng in depth [24]. Interviews are the primary means of data collection [25] during the fieldwork phase and a total of 19 informants were identified via chain referral sampling [26]. The informants included representatives from Qiangsheng's top management, organizational IT function, and various business units (e.g., Asset Management and Human Resource (HR) departments). In addition, we interviewed two taxi drivers, five taxi/ridesharing users, and two industry insiders who were intimately familiar with the contextual conditions surrounding the taxi industry as well. Each interview took an average of 45 minutes and was conducted with the help of a semistructured interview guide [25] that had a set of standard questions with respect to the development and performance of Qiangsheng since the inception of ridesharing. There were also specific questions for each informant that were tailored based on their role (e.g., the taxi drivers interviewed were asked questions in relation to why they were also driving for ridesharing platforms and, hence, their dual identity) within the organization as well [24]. All the interviews were recorded, transcribed in mandarin, and subsequently translated for data analysis.

Data analysis is being performed concurrently with data collection to take full advantage of the flexibility that the case research method affords [27]. A set of second-order themes 
were first derived from the literature on the sharing economy to serve as a theoretical lens to guide our data collection. These themes consisted of the potential negative implications of the sharing economy that have been raised in the existing literature, which were then conceptually abstracted (i.e., firm-specific, economic, and social implications) into three aggregate dimensions (see [28]). The data collected was then coded using a mix of open, axial, and selective coding [29]. More specifically, open coding was used to assign conceptual labels to our interview data to create a number of first-order concepts. Axial coding was then used to classify the first-order concepts around our existing second-order themes (e.g., "unbalanced regulatory regime"), with new themes created (e.g., "unfulfilled societal role") if the firstorder concepts did not fit with our existing schema. Selective coding was then used to group the second-order themes into the existing aggregate dimensions, which were similarly modified if the second-order themes did not fit with our initial theoretical lens (e.g., social implications was reclassified as "contextual conditions" because the external environment did not merely reflect the influence of ridesharing, but served as a driver of its development as well). Coding was restarted whenever new second-order themes or aggregate dimensions were created. The study is still currently ongoing, but this process of iterating between data, analysis, and theory development will continue until the state of theoretical saturation is reached [27].

\section{Negative Influence of Ridesharing}

Our ongoing study of Qiangsheng suggests that there are contextual conditions that are particularly conducive to the growth of ridesharing platforms in China and the accumulation of resources by these platforms, which give rise to a number of negative outcomes for the traditional taxi company (refer to Figure 1). These negative outcomes, in turn, reinforce the prevailing contextual conditions to form a vicious cycle that exacerbates the negative influence of the ridesharing platforms even further. We describe and explain our findings in detail in the stream of reporting that follows.

4.1. Contextual Conditions Favorable to the Growth of Ridesharing in China. The taxi industry in Shanghai is an established and mature sector with a history of over 100 years. And because taxis are largely seen as a means of public transportation that plays an important societal role, the industry is subject to stringent government oversight and regulatory control. For instance, the Shanghai government has a cap on taxi fares that has remained unchanged for around a decade, and like most other cities in China, it is both expensive and difficult to obtain a taxi license (see [30]). In contrast, the Chinese government tends to adopt a permissive attitude toward new technology-enabled businesses so as to avoid stifling innovation (see [31]). This has resulted in an unbalanced regulatory regime that is highly favorable to the ridesharing platforms. The HR Manager of Qiangsheng provided an example: "the government regulations are not helping. For example, drivers from other provinces cannot drive taxis, but the rule does not apply to Didi (China's de facto ridesharing platform). Because of this, our business is like stagnant water. We do not have new people joining this profession. This affects the viability of our business."

At the same time, the high smartphone penetration in China has induced a shift in consumer preferences, as the convenience of hailing a ride in real time with just a few swipes and finger taps via a ridesharing app presents a compelling value proposition for the majority of the country's smartphone users. As a result, there is a substitution effect (see [19]) at work in relation to the public's choice of transportation, and the fact that China now also has a sophisticated transportation network in place is preventing traditional taxi businesses like Qiangsheng from taking steps to ameliorate the situation (i.e., in contrast to the findings of [20]). The Vice-President (VP) of Operations at Qiangsheng explained: "people tend to take the trains if the distance is more than $10 \mathrm{~km}$. For distances around $4-5 \mathrm{~km}$, people tend to use Didi, and for distances below $3 \mathrm{~km}$, people tend to use bicycles or bike shares (e.g., Mobike). Therefore, you can see that the demand for taxis is not very high."

The shifting consumer preferences, in tandem with the unbalanced regulatory regime, presented conditions that were highly conducive to the emergence and business growth of ridesharing platforms such as Didi. In addition, these factors facilitated resource accumulation on the part of the platforms as well because they presented better opportunities for income generation, and there was a lack of participatory barriers (e.g., few regulations preventing anyone from becoming a Didi driver, echoing [7]). The VP of Operations provided an illustration: "Didi drivers are able to earn about CNY\$20k monthly, compared to just CNY\$7-8k for taxi drivers. Not only that, Didi has flexible working hours, while for taxi drivers, you work very long hours. Because of these (differences), many drivers are preferring to drive for Didi than taxi companies." Consequently, the ridesharing platforms in Shanghai were able to proliferate and grow rapidly, which had severe implications for the business of Qiangsheng.

\subsection{The Negative Implications of Ridesharing on Qiangsheng.} More specifically, our informants indicated that the rise of ridesharing platforms gave rise to at least four negative outcomes for Qiangsheng. First, it resulted in business stagnation, due to increased business competition and the loss of revenue. This finding is in line with previous studies on the impact of the sharing economy on incumbent firms (e.g., $[8,19])$ and may be attributed to the enhanced value proposition and lower prices of the ridesharing platforms. The Communist Party Secretary of Qiangsheng described the current situation: "since 2015, our business has not been earning profits and now we have a net loss. This is because we use our (taxi) business revenue to subsidize our drivers... Competition is unfair because these ridesharing platforms are using their massive capital base (from venture capital investments) to keep their prices low... They are burning money 


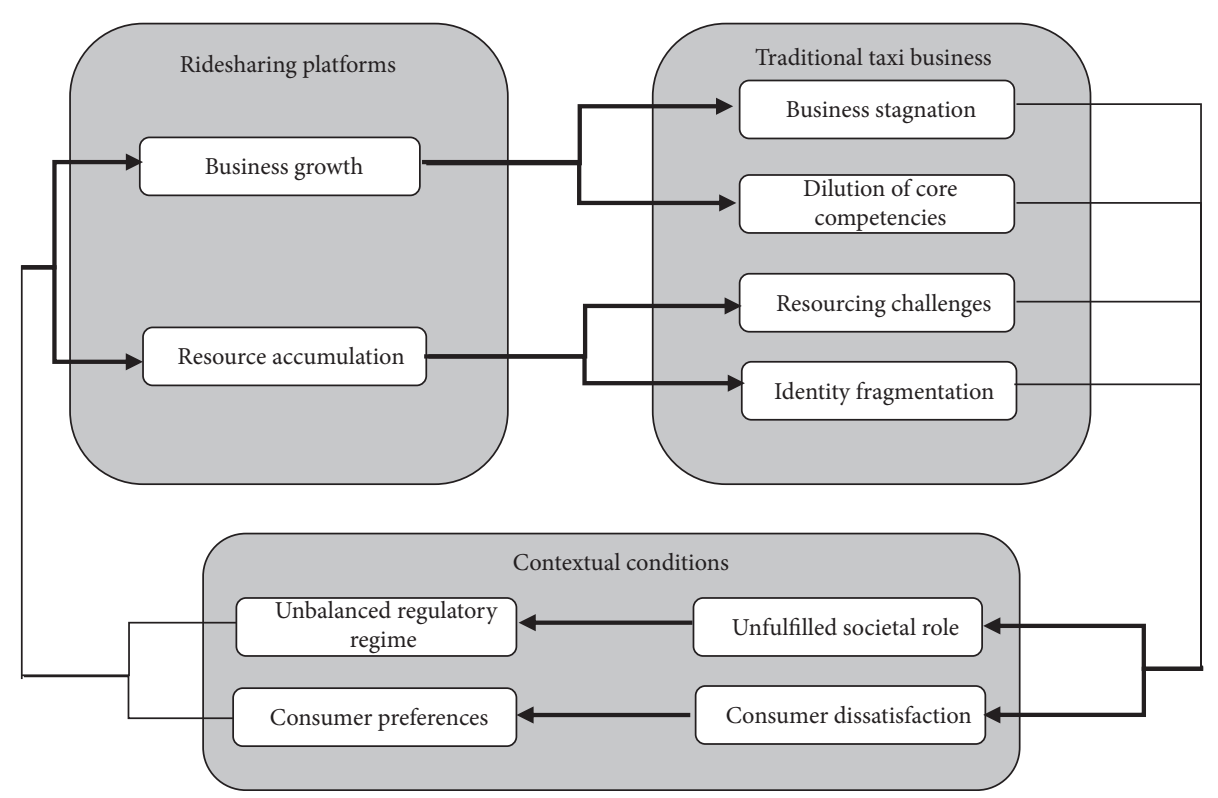

FIgURE 1: The negative economic and social implications of ridesharing.

and operating at a loss to acquire customers and there is no way we can compete with that!"

Second, with the stagnation of its taxi business, Qiangsheng was forced to diversify into a variety of unrelated businesses to maintain its profitability, which resulted in the dilution of core competencies. In particular, as both a market and technology leader within the industry, Qiangsheng has acquired and maintained a number of critical organizational and technological capabilities over the years. However, because its corporate attention is now focused on the development of its other business divisions (e.g., its travel and property businesses), the development of those capabilities has been curtailed, if not neglected. One of the industry insiders we interviewed described this development: "because of low profits and stagnation, there is a need to reform their business or their (taxi) business will not be able to survive in the next 5 years. They are diversifying into other businesses. For example, they are aiming to be a high-end commercial travel service provider, integrating transport, meeting facilities, advertising, and travel services together". This finding resonates with Helfat and Peteraf's [32] assertion that while related diversification can allow for the renewal or redeployment of core competencies, unrelated diversification can lead to their retirement or retrenchment (i.e., gradual decline). In other words, the dilution of its core competencies may affect Qiangsheng's ability to operate and compete with the ridesharing platforms even further.

Third, because Qiangsheng and the ridesharing platforms operate within the same organizational niche, defined as a multi-dimensional space where organizations with the same productive capacities and resource requirements compete [33], when the latter is finding it easier to accumulate resources, it naturally follows that Qiangsheng would be confronted with resourcing challenges. As indicated in the evidence presented previously, ridesharing drivers not only enjoy flexible working hours but also have the potential to make an income that is twice that of a traditional taxi driver. Coupled with the fact that Qiangsheng is prevented by regulations from hiring drivers from other provinces to replenish or renew its existing labor pool, these factors make it very difficult for the firm to acquire the resources it needs, which will become more of a problem in the future as the average age of Qiangsheng's drivers is high (over 50 years of age), with many close to retirement. A taxi driver we interviewed explained: "nobody wants to be a taxi driver anymore. The younger generation, most of them are technology-savvy, and they know how to use Didi well. . . It is hard to find someone like me who just drives a taxi and is not on Didi (at the same time)... Most of the people like me are close to retiring."

Fourth, not only is Qiangsheng finding it challenging to acquire the resources it needs, but it is facing difficulties in retaining its resources as well as its business stagnates and there are no viable means of stemming the outflow of resources. The Deputy General Manager of Qiangsheng explained: "we cannot tell our drivers to stop using Didi. We can only offer incentives like long service awards... and make house visits. . to let the drivers know that their services are valued... But the effectiveness of these incentives is limited... I think it is natural to be drawn to where the material rewards are." As a result, particularly in relation to their pool of drivers, most of their drivers are now not only driving for Qiangsheng but also operating on ridesharing platforms as well. This has caused the issue of identity fragmentation, which we define as the breakdown of the original professional identity as the result of taking on a new occupational role. Identity fragmentation is especially problematic for Qiangsheng because it may result in conflicted loyalties and 
the prioritization of objectives beyond that of the firm [34], which may limit the options of Qiangsheng for competing with the ridesharing platforms even further.

4.3. The Formation of a Vicious Cycle. The four negative outcomes for Qiangsheng, in turn, affected the broader environment in which the firm operates. In particular, beyond their economic contributions, taxi businesses tend to have important social responsibilities as well [35]. The Manager of the Asset Management Department of Qiangsheng provided an example: "during Chinese New Year, Didi drivers who come from other provinces are not working because they are back home for the holidays. Because of this, many customers are unable to get a Didi, and there is only us, the state-owned taxi business, that is reliable and able to provide taxi services for customers. During the time, we even have to subsidize our drivers out of our own pockets to encourage them to work. "However, due to the stagnation of its business, the dilution of its core competencies, and its inability to acquire and retain resources, Qiangsheng's ability to fulfil those responsibilities has been curtailed.

In other words, with fewer drivers and taxis on the road, there is an unfulfilled societal role that was once taken on by traditional taxi businesses like Qiangsheng. And when societal needs have to be met, the government will be forced to intervene, which will tend to further reinforce the unbalanced regulatory regime that is in place. For example, at present in Shanghai, only taxi businesses are required by law to put vehicles out on the roads during the major public holidays. Moreover, if there are fewer taxis because traditional taxi companies are forced to scale back their business, it may cause consumer dissatisfaction because their ability to access the service is reduced, especially among the digitally excluded (e.g., elderly and disabled passengers). One of the taxi/ridesharing users we interviewed explained: "my elderly parents who do not know how to use the Didi app are now finding it very difficult to catch a taxi. I have to book a taxi on their behalf, which can be very frustrating for them because I may not always be by their side." And because taxis are both a taken-for-granted institution and a clearly marked sight on the road, the negative responses toward an inability to catch a ride may be especially targeted at the traditional taxi businesses (as opposed to unmarked ridesharing cars or a distant ridesharing platform), which may increase the consumer preferences for ridesharing even further. These effects close a loop on a vicious cycle that will exacerbate the negative influence of the ridesharing platforms.

\section{Discussion and Concluding Remarks}

The sharing economy is constrained by whimsical ideas about decentralized social markets. Any fair assessment of the sharing economy should recognize a series of specific benefits that are also emphasized by economists and regulators, including but not limited to maximizing the utility of personal assets, flexible work schedules, (some) income security, increasing the quality and quantity of available goods and services through greater competition, and local access to new infrastructure resources [36]. Therefore, at one level, we should regard the sharing economy as a new form of technology-driven business. In fact, sharing does have many advantages implied by its supporters. However, at another level, we must also remain vigilant about the negative impact of sharing economy.

While our study is still in progress, our work to date already hints at a number of potential theoretical contributions. First, the process model developed based on our preliminary data not only is a conceptual innovation but also presents an overview of the negative economic and social implications of ridesharing in China. More specifically, our model suggests that the ascendency of ridesharing platforms can lead to (1) business stagnation, (2) the dilution of core competencies, (3) resourcing challenges, and (4) identity fragmentation for a traditional taxi business, which may reinforce the prevailing contextual conditions that favor the growth of ridesharing even further. In addition, none of the factors and relationships identified in our study appear to be specific to ridesharing or China, which suggests that our process model can potentially advance our understanding of the dark side of the sharing economy [7] beyond its specific context as well. Second, our study not only corroborates the findings of previous studies (e.g., $[8,19]$ ) but also presents an empirically supported explanation "to tell the story of how (the outcome) occurs whenever it does occur" ([37], p. 37). With an understanding of the links of the vicious cycle uncovered, it is hoped that policy makers and leaders of the traditional businesses that are being displaced by the sharing economy can use our research to identify ways of breaking the cycle, so that the traditional businesses can survive, or even thrive, in spite of the growth of ridesharing, and continue to fulfill their important economic and societal roles. In addition, it is hoped that our process model would be a useful reference for the owners and managers of traditional businesses that are being affected by the emergence of the sharing economy as well. For instance, our process model suggests that while diversifying into other potentially more profitable lines of businesses may be a short-term solution to mitigate the negative financial impact of the sharing economy (see $[8,19]$ ), it may in fact cause the dilution of core competencies for a traditional business. As such, we contend that diversification decisions should be carefully considered even if they present a quick fix, and perhaps resources would be more optimally leveraged in the long run if they were invested in reinforcing the core competencies of a traditional business instead [38].

This study is not without its limitations. In particular, although the single case research method adopted in this study is a "typical and legitimate endeavor" ([39], p. 231) in qualitative information systems research, the generalizability of our findings and process model may be an issue that is associated with the singular context of our study [40]. As such, our future research will be centered on extending and validating our process model with the collection and analysis of additional data from Qiangsheng, as well as a variety of stakeholders (e.g., passengers, taxi drivers, and representatives of ridesharing platforms) from contexts beyond the one studied here (e.g., the taxi industry in Singapore, which 
appears to have reached an ideal equilibrium where a dominant ridesharing platform is thriving alongside a thriving traditional taxi industry). The boundary conditions and implications of our model will also be explored in greater depth through an ongoing literature review and further analyses of our data. By collecting and incorporating further data, and subjecting the data to more in-depth analyses, we hope to refine our process model further so that a more holistic understanding of the negative implications of the sharing economy can emerge.

\section{Data Availability}

The data used to support the findings of this study are available from the corresponding author upon request.

\section{Disclosure}

An earlier version of this work was presented as an abstract at the International Conference on Information Systems (ICIS), 2019.

\section{Conflicts of Interest}

The authors declare that they have no conflicts of interest.

\section{References}

[1] J. Schor, "Debating the sharing economy," Journal of SelfGovernance and Management Economics, vol. 4, no. 3, pp. 7-22, 2016.

[2] J. Hamari, M. Sjöklint, and A. Ukkonen, "The sharing economy: why people participate in collaborative consumption," Journal of the Association for Information Science and Technology, vol. 67, no. 9, pp. 2047-2059, 2016.

[3] M. A. Cusumano, "The sharing economy meets reality," Communications of the ACM, vol. 61, no. 1, pp. 26-28, 2018.

[4] A. Witt, N. Suzor, and P. Wikström, "Regulating ride-sharing in the peer economy," Communication Research and Practice, vol. 1, no. 2, pp. 174-190, 2015.

[5] The Economist, "The rise of the sharing economy," The Economist, London, UK, 2013, https://www.economist.com/ leaders/2013/03/09/the-rise-of-the-sharing-economy.

[6] A. Rinne, The Dark Side of the Sharing Economy, World Economic Forum, Cologny, Switzerland, 2018, https://www. weforum.org/agenda/2018/01/the-dark-side-of-the-sharingeconomy/.

[7] A. Malhotra and M. Van Alstyne, "The dark side of the sharing economy ... and how to lighten it," Communications of the ACM, vol. 57, no. 11, pp. 24-27, 2014.

[8] G. Zervas, D. Proserpio, and J. W. Byers, "The rise of the sharing economy: estimating the impact of Airbnb on the hotel industry," Journal of Marketing Research, vol. 54, no. 5, pp. 687-705, 2017.

[9] B. Cohen and J. Kietzmann, "Ride on! Mobility business models for the sharing economy," Organization \& Environment, vol. 27, no. 3, pp. 279-296, 2014.

[10] B. Hartl, E. Hofmann, and E. Kirchler, "Do we need rules for "what's mine is yours"? Governance in collaborative consumption communities," Journal of Business Research, vol. 69, no. 8, pp. 2756-2763, 2016.
[11] R. Belk, "You are what you can access: sharing and collaborative consumption online," Journal of Business Research, vol. 67, no. 8, pp. 1595-1600, 2014.

[12] T. Puschmann and R. Alt, "Sharing economy," Business \& Information Systems Engineering, vol. 58, no. 1, pp. 93-99, 2016.

[13] B. Barann, D. Beverungen, and O. Müller, "An open-data approach for quantifying the potential of taxi ridesharing," Decision Support Systems, vol. 99, no. 1, pp. 86-95, 2017.

[14] J. Cramer and A. B. Krueger, "Disruptive change in the taxi business: the case of Uber," American Economic Review, vol. 106, no. 5, pp. 177-182, 2016.

[15] G. Zhu, K. K. F. So, and S. Hudson, "Inside the sharing economy," International Journal of Contemporary Hospitality Management, vol. 29, no. 9, pp. 2218-2239, 2017.

[16] F. T. C. Tan, M. Cahalane, B. Tan, and J. Engelert, "How GoGet carshare's product-service system is facilitating collaborative consumption," MIS Quarterly Executive, vol. 16, no. 4, pp. 265-277, 2017.

[17] C. J. Martin, "The sharing economy: a pathway to sustainability or a nightmarish form of neoliberal capitalism?" Ecological Economics, vol. 121, no. 1, pp. 149-159, 2016.

[18] W. Kathan, K. Matzler, and V. Veider, "The sharing economy: your business model's friend or foe?" Business Horizons, vol. 59, no. 6, pp. 663-672, 2016.

[19] H.-H. Chang, "The economic effects of Uber on taxi drivers in Taiwan," Journal of Competition Law \& Economics, vol. 13, no. 3, pp. 475-500, 2017.

[20] K. Kim, C. Baek, and J.-D. Lee, "Creative destruction of the sharing economy in action: the case of Uber," Transportation Research Part A: Policy and Practice, vol. 110, no. 110, pp. 118-127, 2018.

[21] G. Walsham, "Interpretive case studies in IS research: nature and method," European Journal of Information Systems, vol. 4, no. 2, pp. 74-81, 1995.

[22] S. Rynes and R. P. Gephart Jr., "From the editors: qualitative research and the academy of management journal," Academy of Management Journal, vol. 47, no. 4, pp. 454-462, 2004.

[23] J. Gerring, "Case selection for case-study analysis: qualitative and quantitative techniques," in The Oxford Handbook of Political MethodologyOxford University Press, Oxford, UK, 2009, http://www.oxfordhandbooks.com/view/10.1093/oxfor dhb/9780199286546.001.0001/oxfordhb-9780199286546-e-28.

[24] S. L. Pan and B. Tan, "Demystifying case research: a structured-pragmatic-situational (SPS) approach to conducting case studies," Information and Organization, vol. 21, no. 3, pp. 161-176, 2011.

[25] M. D. Myers and M. Newman, "The qualitative interview in IS research: examining the craft," Information and Organization, vol. 17, no. 1, pp. 2-26, 2007.

[26] P. Biernacki and D. Waldorf, "Snowball sampling: problems and techniques of chain referral sampling," Sociological Methods \& Research, vol. 10, no. 2, pp. 141-163, 1981.

[27] K. M. Eisenhardt, "Building theories from case study research," Academy of Management Review, vol. 14, no. 4, pp. 532-550, 1989.

[28] D. A. Gioia, K. G. Corley, and A. L. Hamilton, "Seeking qualitative rigor in inductive research," Organizational Research Methods, vol. 16, no. 1, pp. 15-31, 2013.

[29] A. Strauss and J. Corbin, Basics of Qualitative Research: Techniques and Procedures for Developing Grounded Theory, Sage, Thousand Oaks, CA, USA, 2nd edition, 1998.

[30] L. Kuo, Chinese Taxi Drivers Attempt Suicide to Protest the Government's Heavy-Handed Cab Monopoly, Quartz, New 
York City, NY, USA, 2015, https://qz.com/377047/chinesetaxi-drivers-attempt-suicide-to-protest-the-governmentsheavy-handed-cab-monopoly/.

[31] E. Wilson, "China takes a swipe at the fintech sector,"Euromoney, 2018, https://www.euromoney.com/article/b18ws9x3trz4gz/chin a-takes-a-swipe-at-the-fintech-sector?copyrightInfo=true.

[32] C. E. Helfat and M. A. Peteraf, "The dynamic resource-based view: capability lifecycles," Strategic Management Journal, vol. 24, no. 10, pp. 997-1010, 2003.

[33] J. A. C. Baum and J. V. Singh, "Organizational niches and the dynamics of organizational mortality," American Journal of Sociology, vol. 100, no. 2, pp. 346-380, 1994.

[34] C. M. Fiol, M. G. Pratt, and E. J. O'Connor, "Managing intractable identity conflicts," Academy of Management Review, vol. 34, no. 1, pp. 32-55, 2009.

[35] Deloitte Access Economics, The Economic and Social Contribution of the NSW Taxi Industry, Deloitte Access Economics Pty Ltd, London, UK, 2013, https://www2.deloitte.com/content/dam/ Deloitte/au/Documents/Economics/deloitte-au-economics-econ omic-social-contribution-nsw-taxi-industry-121213.pdf.

[36] C. Ryan and A. Rosenblat, "The taking economy: uber, information, and power," Columbia Law Review, vol. 117, no. 6, pp. 1623-1690, 2017.

[37] L. B. Mohr, Explaining Organizational Behavior, Jossey-Bass, San Francisco, CA, USA, 1982.

[38] V. Abhishek, J. Guajardo, and Z. Zhang, "Business models in the sharing economy: manufacturing durable goods in the presence of peer-to-peer rental markets," SSRN Working Papers, https://papers.ssrn.com/sol3/papers.cfm?abstract_ $\mathrm{id}=2891908,2019$.

[39] A. S. Lee and R. L. Baskerville, "Generalizing generalizability in information systems research," Information Systems Research, vol. 14, no. 3, pp. 221-243, 2003.

[40] G. Walsham, "Doing interpretive research," European Journal of Information Systems, vol. 15, no. 3, pp. 320-330, 2006. 